\title{
ENUNCIADOS SOBRE LA EDUCACIÓN MEDIA TÉCNICO-PROFESIONAL Y SU LUGAR B EN EL DISPOSITIVO EDUCACIONAL
}

\author{
MARÍA JEsÚs MONTECINOS*
}

\begin{abstract}
RESUMEN
Este artículo tiene como propósito cuestionar algunas formulaciones discursivas que circulan sobre la educación media técnico-profesional en Chile y que la produce como una alternativa de segunda categoría. A partir de un análisis de base foucaultiana, se relevan tres líneas discursivas que distribuyen a las y los estudiantes como otras y otros dentro de nuestro dispositivo educacional: la circunscripción de la entrada a la formación media técnico-profesional a una elección, la supuesta indeseabilidad de esta modalidad y el reconocimiento simultáneo de constricciones bajo la formulación de esta misma entrada como un imperativo.
\end{abstract}

PALABRAS ClAVE: SUBJETIVIDADES, DISCURSO, CLASE SOCIAL

\footnotetext{
* Doctora (c) en Educación, universidades Alberto Hurtado y Diego Portales, Chile; becaria doctorado nacional CONICYT. Docente en las facultades de Educación y Filosofía y Humanidades, Universidad Alberto Hurtado, Chile. Correo electrónico: mmontecino@uahurtado.cl, jesu.montecinos@gmail.com
} 


\title{
ENUNCIADOS SOBRE A EDUCAÇÃO PROFISSIONAL TÉCNICA DE NÍVEL MÉDIO E SEU LUGAR SECUNDÁRIO NO SISTEMA EDUCACIONAL
}

\begin{abstract}
RESUMO
O objetivo deste artigo é questionar algumas formulações discursivas que circulam sobre a educação profissional técnica de nível médio no Chile e o que a produz como uma alternativa de segunda categoria. A partir de uma análise de base foucaultiana, são reveladas três linhas discursivas que distribuem às e aos estudantes como outras e outros dentro de nosso sistema educacional: a circunscrição do ingresso à formação da educação profissional técnica de nível médio a uma eleição, a suposta indesejabilidade desta modalidade e o reconhecimento simultâneo de constrições sob a formulação deste mesmo ingresso como um imperativo.
\end{abstract}

PALAVRAS-CHAVE: SUBJETIVIDADES, DISCURSO, CLASSE SOCIAL.

\section{STATEMENTS ABOUT CAREER AND TECHNICAL EDUCATION IN HIGH SCHOOL AND ITS SECOND - RATE POSITION IN THE EDUCATION SYSTEM}

\begin{abstract}
This article aims to question certain discursive formulations around career and technical education in high school in Chile relegating it to a second-rate alternative. From a Foucauldian analysis, three discursive lines distributing students as 'the others' within our education system are drawn: the circumscription of joining career and technical education courses in high school as a choice, the alleged undesirability of this modality, and the simultaneous recognition of restrictions under its conception as an imperative.
\end{abstract}

KEYWORDS: SUBJECTIVITIES, DISCOURSE, SOCIAL CLASS. 


\section{INTRODUCCIÓN}

\#MejoraLaTécnica: No permitamos que la mitad de la educación chilena esté olvidada por completo. Si Chile no puede vivir sin sus técnicos, ¿por qué no les damos el lugar que merecen? Profesionales y técnicos debieran recibir la misma valoración social y económica, sin sufrir una brecha salarial abismante. Esta es la realidad de los países que han

logrado que la educación técnica sea una opción de vida.

(Mirentxu Anaya, presidenta ejecutiva de Educación 2020, s.f.)

La educación media técnico profesional es una importante opción vocacional para una gran cantidad de estudiantes y la base fundamental para apoyar la economía y competitividad del país. El desafío es transformarnos en una opción real, de que es una gran opción para los estudiantes.

(Marta Hernández, directora liceo técnico-profesional, 2015)

Debemos construir una educación media TP que debe ser una opción válida para nuestros jóvenes.

(César Muñoz, Centro de Estudios Avanzados sobre Justicia Educacional, 2013) ${ }^{1}$

Como sabemos, nuestro sistema de educación está atravesado por profundas desigualdades y uno de sus escenarios más relevantes es la diferenciación que se produce en los dos últimos grados de la educación media, entre las modalidades científico-humanista y técnico-profesional. En Chile, esta última representa el $38 \%$ de la matrícula regular de jóvenes que estudian en tercero y cuarto medio. Sin embargo, si se considera solo a la educación pública o a los tres primeros quintiles, esta cifra aumenta a 55\% (Mineduc, 2018) y $60 \%$ (Larrañaga, Cabezas y Dussaillant, 2014), respectivamente. Vinculada a la segmentación de clase que articula ambas modalidades educativas, existe también una profunda desigualdad académica entre las y los estudiantes de la educación media técnico-profesional y sus pares de la formación científicohumanista (Farías y Carrasco, 2012; Larrañaga, Cabezas y Dussaillant, 2013). De acuerdo con Larrañaga y otros (2013), estas características son consistentes con la noción tradicional de la educación media técnico-profesional como

1 Cursivas añadidas. 
modelo formativo terminal, orientado al ingreso inmediato al mundo laboral. Sin embargo, aunque en la década pasada esta visión se mantuvo predominante en los actores educativos que componen este sistema (Sepúlveda, Ugalde y Campos, 2009, 2010), las y los egresados de la educación media técnicoprofesional han sido parte fundamental del proceso de masificación experimentado por nuestra educación superior. De acuerdo con los datos del Mineduc, el porcentaje de estas y estos estudiantes que continúan estudios superiores ha aumentado significativamente, pasando de un 30,4\% el año 2005 a un $57 \%$ el año 2015.

Esta importante transformación de la educación superior y las trayectorias de las y los estudiantes de la educación media técnico-profesional, junto con la rabia social expresada ante las desigualdades de nuestro sistema educativo, han generado una paulatina visibilización de esta modalidad de estudios, tanto en los debates educacionales, como también en el desarrollo de investigaciones (ver, por ejemplo: Farías y Sevilla, 2015; Larrañaga et al., 2013, 2014; Sepúlveda, 2016; Sepúlveda y Valdebenito, 2014; Sevilla, 2014; Sevilla, Farías y Weintraub, 2014). Sin embargo, este proceso continúa siendo tímido y la educación técnico-profesional sigue ocupando un lugar marginal en los discursos políticos y la academia. Como consecuencia, tenemos un conocimiento precario sobre ámbitos relevantes de esta modalidad. En particular, existe un déficit de investigaciones de naturaleza cualitativa que indaguen las subjetividades, deseos y valoraciones de quienes egresan de este sistema. Esto no es menor si además consideramos que la mayoría de quienes realizamos investigación o política en el campo de la educación chilena provenimos, precisamente, del modelo científico-humanista.

En este contexto, cuando en un seminario destinado a la educación técnico-profesional en Chile, escuché decir que sabíamos que la educación media en esta modalidad era, en su estado actual, «la opción B, la opción para el más flojito y los pobres», me pregunté qué se estaba diciendo y cómo lo sabíamos. Me pregunté si alguna de las entrevistadas de mi investigación doctoral, todas egresadas de la educación media técnico-profesional, se sentiría identificada con esta idea expresada al pasar. Me pregunté también, hasta qué punto la manera en que nos referimos a estas y estos estudiantes, incluso desde la más genuina preocupación, contribuye a sedimentar una formulación patológica de ellas y ellos. ¿Qué decimos cuando damos a entender que en su estado actual la educación media técnico-profesional no es una opción válida, no es una opción de vida o que no es una opción real? ¿De quiénes hablamos cuando decimos que esta modalidad es la opción B? ¿Para quiénes es la opción $B$ ? ¿Cuál es la opción $A$ ? ¿Existe la posibilidad de que algunas y algunos jóvenes y sus entornos valoren a la educación media técnico-profesional por sobre la formación científico-humanista, y que no constituya una opción $B$, sino una opción de vida real, válida y deseada, también en su estado actual? Cuando decimos y creemos que es una opción $B$, ¿cuáles son las y los sujetos posibles que podemos extraer de eso? ¿Qué formas específicas de subjetivación hacemos 
circular?

Me gustaría proponer en este artículo, que esta manera de aproximarnos a la educación media técnico-profesional no es escasa ni arbitraria, sino que constituye el efecto de una regla de inteligibilidad que circula dentro de nuestro dispositivo educacional, imputando significados a la educación media técnicoprofesional y sus estudiantes, sobre todo para quienes no fuimos formadas y formados en ella. Y que, al mismo tiempo, es totalmente insuficiente para dar cuenta de la complejidad y diversidad de experiencias y valoraciones de quienes efectivamente son educadas y educados en esta modalidad.

\section{Perspectiva teórica}

El análisis que presento a continuación estuvo orientado teóricamente por las reflexiones instaladas por Foucault en torno al saber, la naturaleza discursiva del sujeto y, en particular, la metodología arqueológica formulada al comienzo de su trabajo. También por la interpretación realizada por Deleuze sobre la misma.

De acuerdo con Foucault (1984a), el sujeto corresponde a los modos en que los seres humanos devenimos formados, clasificados y constituidos para devenir inteligibles. A diferencia de la manera como tendemos a usar el concepto cotidianamente bajo la formulación "cada humano es un sujeto» en Foucault, por el contrario, cada persona va siendo sujeto de múltiples formas, las cuales van variando de acuerdo con las formaciones y sedimentaciones sociales en las que va siendo producido. Alejado de cualquier consideración universal o esencialista del ser humano, el sujeto propuesto por Foucault es, en cambio, de naturaleza variable y discursiva.

Es el discurso, aquello que da condiciones para ser y saber en tanto forma. Tal como Butler (2001) explica, los seres humanos ocupamos el lugar del sujeto, adquiriendo inteligibilidad solo en tanto que estamos previamente establecidos en el lenguaje. El sujeto ofrece la oportunidad lingüística para que el ser humano alcance y reproduzca la inteligibilidad, la condición lingüística de su existencia (Butler, 2001). Así, los sujetos constituyen los modos posibles en que las personas devenimos distinguibles, fijadas, estabilizadas y clasificadas, para existir como formas inteligibles de acuerdo con los significados imputados por un discurso. Desde esta perspectiva, cada sujeto (hombre, mujer, joven, trabajadora, estudiante de educación media técnicoprofesional, etc.) es una producción social, cultural e históricamente situada, que varía de acuerdo con el corpus discursivo en que es expresado y que establece sus posibilidades e imposibilidades.

Tal como lo propone Foucault (1970), los discursos corresponden a grandes corpus constituidos por unidades discursivas denominadas enunciados. Estas unidades elementales de todo corpus discursivo no están simplemente 
dadas en lo que decimos. Lo que se da inmediatamente en el lenguaje son palabras, frases y proposiciones. Estas unidades gramaticales tienen una naturaleza distinta a la de los enunciados. Estos últimos no son significantes, sino funciones que de hecho hacen posible (o imposible) el significado para cualquier unidad gramatical. Cada enunciado, como modo distinto de función y en relación con otros enunciados, establece reglas, conformando las posibilidades de inteligibilidad para cada sujeto. De esta manera, «mujer», «joven», «estudiante», etc., devienen formas subjetivas que encuentran sus significados específicos en los corpus discursivos en que son producidas, los cuales posibilitan al mismo tiempo en que constriñen aquello que podemos decir, escribir y pensar sobre ellas (Ball, 2012).

Así mismo, en la obra de Foucault, las líneas discursivas o enunciados forman parte de unidades más complejas denominadas dispositivos. Estos últimos son sistemas, siempre heterogéneos, conformados por los discursos junto a las instituciones, las expresiones legales, los edificios y materialidades y que encuentran sus conexiones en el diagrama estratégico, es decir, los puntos de poder que los componen (Foucault, 1984b).

En este artículo tomo la formulación opción $B$ para poder nombrar un enunciado, que creo forma parte medular del corpus discursivo actual sobre la educación en nuestro país. Con esto, no quiero decir que sea literalmente «opción B» el enunciado; tal como señala Deleuze (1987, 2013), los enunciados no están directamente expresados, hay que extraerlos y están, como establece Foucault (1970), en el límite del lenguaje. Simplemente tomo esta fórmula para poder nombrar una unidad discursiva que establece un tipo de regularidad dentro de nuestro dispositivo educacional, imputando reglas de inteligibilidad y significado a la educación media técnico-profesional como modalidad educacional y a quienes desarrollan sus trayectorias educativas dentro de ella. Como contrapunto discursivo extraigo también un segundo enunciado, el cual denomino se aprende haciendo, con esto, mi objetivo es presentar una manera alternativa de comprender la entrada a la educación media técnico-profesional, a la luz de otras líneas discursivas que también circulan dentro de nuestro dispositivo educacional.

\section{ESTUDIO Y PERSPECTIVA METODOLÓGICA}

Para el análisis me baso en datos empíricos de mi investigación doctoral, la cual corresponde a un estudio cualitativo que tuvo como objetivo principal comprender las experiencias de transición de mujeres desde la educación media técnico-profesional hacia la educación superior y el trabajo. Los datos fueron producidos a través de tres rondas de entrevistas en profundidad realizadas durante los años 2016 y 2017 a ocho mujeres, todas egresadas de la educación media técnico-profesional el año 2011, en la Región Metropolitana, y estudiantes de la educación superior el año 2015. Vanesa, 
Ruth, Margarita, Ana, Carolina, Denise, Ximena y Beatriz fueron los nombres asignados para cada una de las participantes durante la investigación y son los mismos utilizados en este artículo.

Además de las entrevistas, en este texto el análisis incluyó material empírico de documentación respecto a lo dicho sobre la educación técnicoprofesional durante los últimos años. Esto incluyó columnas de opinión, documentos del Ministerio de Educación y registros propios realizados durante toda la investigación.

La perspectiva metodológica que orientó el trabajo analítico estuvo alineada con las motivaciones teóricas a las que me referí recién, es decir, al método ofrecido por Foucault bajo la formulación de una arqueología discursiva (1970), así como también su interpretación posterior realizada por Deleuze $(1987,2013)$. Así mismo, la investigación estuvo muy influenciada por parte del trabajo feminista dentro de la investigación educativa británica, de base también foucaultiana. Los trabajos de Lawler (2000), Skeggs (1995), Youdell (2004) y Walkerdine, Lucey y Melody (2001), entre muchas otras, fueron una fuente de reflexión analítica fundamental para pensar los cómo del proceso metodológico y la consideración de mis propias subjetividades en juego. Tal como señala Foucault (2002), el análisis de las formas discursivas debe realizarse desde la consideración de que el sujeto que conoce, aquello que conoce y la propia forma de conocimiento establecida están implicados ya en sedimentaciones históricas y constreñidos por los marcos discursivos en que se despliega. En este sentido, trabajar desde la afirmación de esta perspectiva ha significado asumir también el ejercicio sistemático de considerar mis propias subjetividades, pero sobre todo hacer un uso crítico de estas. El análisis que presento a continuación es el resultado de parte de este mismo ejercicio.

A continuación, presento tres líneas discursivas, estas son: la circunscripción de la entrada a la formación media técnico-profesional a una elección, la supuesta indeseabilidad de esta modalidad y el reconocimiento simultáneo de constricciones bajo la formulación de esta misma entrada como un imperativo. Estas tres líneas, desde mi perspectiva, son aquello que es articulado por el enunciado de la opción B. Luego, como contrapunto, presento el enunciado del se aprende haciendo. Este moviliza reglas de inteligibilidad distintas y nos ofrece un marco alternativo para comprender las trayectorias educativas de las y los estudiantes de la educación media técnico-profesional. 


\section{ANÁLISIS Y RESULTADOS}

\subsection{NO FUE OPCIÓN B}

Una de las líneas discursivas que despliega la opción $B$ es la circunscripción de las experiencias de entrada de las y los estudiantes a la educación media técnico-profesional a una elección:

En los niveles socio-económicos más vulnerables eligen la modalidad escolar EM-TP [Educación media técnico-profesional] aproximadamente el $60 \%$ de la población.

(Ovalle, 2018)

En Educación Media Técnico Profesional, 4 de cada 10 jóvenes elige un liceo técnico profesional. Esto es especialmente relevante en la Educación Pública (Municipales y Administración Delegada), donde el 56\% de los estudiantes elige un liceo técnico profesional.

(Mineduc, portal web Educación Técnico-Profesional, noviembre, 2015)²

Se habla de la entrada a la modalidad de estudio en un registro de opciones, formulando las experiencias de entrada de estas y estos jóvenes a la educación media técnico-profesional a una elección donde se presupone, por ejemplo, la visibilidad de la formación científico-humanista. Damos por hecho que es una modalidad conocida por todos y todas. Sin embargo, tres entrevistadas no sabían cómo nombrarla. Para Vanesa, Denise, Ximena, Beatriz y Margarita, quienes estudiaron en liceos exclusivamente técnico-profesionales, la idea de la formación científico-humanista es abstracta, tal como me dice Denise: vaga. La distinción entre esta última y su modalidad de estudios se estructura fundamentalmente en torno a la posibilidad de entrar a la universidad a partir de la preparación para la PSU. En realidad, con la excepción de Vanesa, esta modalidad educacional solo forma parte de sus relatos cuando yo, como entrevistadora, la introduzco en las conversaciones. Lo mismo ocurre con el registro de opción/elección frente a ambas modalidades. Este solo emerge cuando yo lo introduzco en mis preguntas, e incluso cuando es así, ninguna de estas cinco mujeres expresa que optó, ni por una ni por la otra, y tampoco sienten que sus familias lo hayan hecho:

MJ: ¿Quién decidió que estudiaras en un técnico profesional la educación media? ¿Lo decidiste tú? ¿Lo decidió tu mamá?...

2 Cursivas añadidas. 
D: Nadie, la verdad, fue porque estaba en ese colegio desde quinto básico y me quedé ahí... por la costumbre. Aparte donde vivo no es muy bueno, entonces en ese colegio no tenía mayores problemas, porque en otros colegios que habíamos ido antes con mi hermana, en tercero o cuarto básico, nos pegaban, nos robaban la colación, entonces teníamos miedo y en ese colegio nos sentíamos cómodas y por eso me quedé ahí de quinto básico a cuarto medio.

(Denise, tercera entrevista, abril de 2017)

Al mismo tiempo que la opción $B$ establece una regla discursiva que hace hablar de la entrada a la educación media como una opción/elección, la formula también como indeseable. Por eso es la B, y no la A. Entonces, se asume que, independiente de la posición y subjetividades, la educación científico-humanista y sus saberes ocupan un lugar privilegiado y, en cambio, la formación técnico-profesional padece de una falta educativa. Produciendo así a sus estudiantes como sujetos y sujetas que eligen, sin embargo, la peor opción:

Los datos del Mineduc señalan que 4 de cada 10 jóvenes elige un liceo técnico profesional, pero en la Educación Pública el 56\% opta por esta modalidad. (...) Pero la Educación Técnica pareciera ser la pariente pobre del sistema educativo (...).

(Ivette Arriagada, Grupo Educar, mayo de 2018)

Pero en nuestro país hoy la educación técnica es casi lo que botó la ola. Sería una señal de desarrollo que la educación técnica se eligiera por vocación, atrayendo a estudiantes de todos los colegios: públicos, particulares subvencionados y particulares privados.

(Mirentxu Anaya, presidenta ejecutiva de Educación 2020, s.f.) $)^{3}$

Ninguna de las entrevistadas explica que estudió en la educación media técnico-profesional porque fuera su opción $B$, al mismo tiempo que cada una de ellas reconoce que su experiencia de educación media estuvo culturalmente situada y también constreñida por condiciones materiales. En los relatos de Carolina, Ana y Ruth, quienes estudiaron en liceos polivalentes, el registro de comparación entre ambas modalidades sí emerge $y$, junto con ello, la educación científico-humanista adopta un cuerpo más concreto que forma parte de sus historias de entrada y experiencias en la modalidad técnico-profesional. Cuando en nuestra primera entrevista les pedí que me contaran cómo habían llegado a estudiar a esta modalidad, estas entrevistadas respondieron que estableciendo una relación explícita con la formación científico-humanista. Ana, por ejemplo, me explicó que nunca vio "esa posibilidad, nunca me gustó porque encontraba

3 Cursivas añadidas. 
que era nada, o sea, salir con nada». A Ruth y Carolina tampoco les gustaba, no les «llamaba la atención», querían «salir con algo». Para aquellas que estudiaron en establecimientos polivalentes, al menos parte de la entrada a la educación técnico-profesional sí puede ser vinculada a un recuerdo de elección, pero contrario a la idea de una opción $B$, estas mujeres formulan la comparación para explicar por qué la educación técnico-profesional era la modalidad que ellas deseaban.

Cuando enunciamos la educación técnico-profesional como opción $B$, muchas veces es desde la suposición naturalizada de que la segmentación académica y socioeconómica que atraviesa la modalidad técnico-profesional a nivel sistémico es conocida por todos y todas a nivel singular. Sin embargo, esto no es necesariamente así con la mayoría de las entrevistadas de esta investigación. Solo Margarita estableció un vínculo explícito entre las modalidades y la clase social, asociando a la clase media alta a la modalidad científico-humanista.

Yo creo que una clase social media alta piensa que igual [los liceos técnicoprofesionales] son útiles, pero yo creo que creen que es mejor estos colegios científico- humanistas, porque los están preparando al tiro para ir a dar la PSU y para entrar a la universidad, yo creo que se ve así, no sé si pensará así la misma persona, pero yo creo que la gente... va por clase social.

(Margarita, tercera entrevista, mayo de 2017)

Pero que vaya por clase social, no implica necesariamente que entonces el científico-humanista sea, por defecto, deseable para ella. En algunos momentos, la clase media alta o la clase alta van a exhalar una deseabilidad, una fuerza de atracción en los relatos, pero no en todas sus formulaciones y prácticas. Cuando Margarita distingue a las modalidades a partir de clases sociales, no podemos extraer de eso, tal como el enunciado de la opción $B$ nos sugiere, que Margarita siente que estudió en el técnico-profesional porque no le quedaba otra, o que preferiría haber estudiado en un científico-humanista. Margarita reconoce valoraciones distintas en función de clases sociales, pero también dice que volvería a estudiar en un liceo técnico-profesional si tuviese que entrar nuevamente a la educación media, aun imaginándose en condiciones económicas distintas, y cree que es una buena alternativa para su hijo.

No quiero dar a entender aquí que estoy asumiendo que Margarita es un sujeto neutral con una disposición intrínseca a la educación media técnicoprofesional, y que, si de hecho hubiese estado en condiciones culturales distintas, habría estudiado de todas formas en un técnico-profesional. Tal como señalé, los sujetos no son sustancias, y son producidos por las relaciones de poder/saber que dan forma a sus contextos culturales. En este sentido, no hay una Margarita, independiente de su historia. Pero el ejercicio de volver sobre 
nuestros pasos y fantasear cómo habrían sido las cosas si algo hubiese sido distinto, aunque es siempre ficticio, como experiencia nos habla acerca de cuáles son las fuentes de subjetivación más intensas para hacer una experiencia sobre nosotros mismos. Aquellas experiencias que no podemos soltar, porque nos ofrecen significados para poder entendernos en nuestra versión actual. Al mismo tiempo en que Margarita reconoce las constricciones materiales y las distintas valoraciones implicadas en las posiciones de clase, haber estudiado en la educación media técnico-profesional es una fuente de subjetivación intensa para ella, tal como desarrollaré más adelante, esa modalidad de estudio produjo líneas enunciativas para poder entenderse a sí misma en una relación mucho más afirmativa con su modalidad de estudio, que la que la opción $B$ nos sugiere.

En la opción $B$ subyace o se extrae una fórmula que trasviste el tener con el ser, mirado desde una posición asumida como deseable (la opción A), al mismo tiempo en que desconoce y silencia otros modos de ser. Todos y todas podemos reconocer subjetividades que se encuentran en posiciones de mayor privilegio material que la nuestra, y también sabemos que eso no implica desear esas subjetividades y compartir sus valoraciones, tal como el enunciado que la opción B propone.

Finalmente, en este doble juego de elección e indeseabilidad, el enunciado de la opción $B$ da espacio al reconocimiento de las constricciones estructurales dentro de un corpus discursivo basalmente neoliberal, al establecer la entrada a la modalidad técnico-profesional como imperativa: para los flojitos y los pobres:

Hay una idea errada de que esos jóvenes decidieron libremente estudiar en un liceo TP. Muchas veces estudian allí porque no tuvieron otra opción.

(Francisco Javier Gil, director cátedra UNESCO-USACH de Inclusión en la ES, junio de 2015)

En este gesto enunciativo se expresa el imperativo de una entrada «temprana» al mundo del trabajo. Quienes tienen constricciones económicas deben entrar a trabajar prontamente, ya sea para una inserción definitiva, o durante la continuación de estudios superiores, por eso es para los pobres; y quienes tienen resultados académicos bajos solo pueden optar a una cualificación para el mundo laboral, ya que las proyecciones en la educación superior quedan limitadas por su desempeño escolar, por eso es para los flojitos. En ambas formulaciones, la entrada «temprana» al mundo del trabajo es imperativa, pero además regularizada por un enunciado que la constituye como indeseable desde la opción A; por eso es la opción $B$ y no la $A$, por eso es una entrada «temprana», es decir, anterior, adelantada, prematura, por eso no les queda otra. 
Cuando se relega la educación media técnico-profesional a un lugar B dentro del dispositivo educacional, en parte precisamente por su función con el mundo del trabajo, al mismo tiempo en que esta función, cuando es imperativa, nos parece indeseable, entonces la única forma razonable que les dejamos a sus estudiantes es que estudien especialidades en las que, al menos creen, efectivamente van a desempeñarse. Produciéndolos a través de una racionalización de sus motivos y acciones, asumiendo para ellos una aproximación instrumental respecto a sus propias experiencias educativas en la educación media. Este mecanismo de subjetivación, basado en una racionalización instrumental abre escasamente posiciones legítimas posibles para quienes, por ejemplo, entran a una especialidad para aprenderla, pero no porque quieran trabajar en ella. Si suponemos que la educación media es una experiencia a la que se llega meramente por el reconocimiento de constricciones y la práctica de producir trayectorias instrumentales, entonces corremos el riesgo de desposeerla de cualquier otro valor propio que pueda tener para sus estudiantes y entornos culturales. Limitando, al mismo tiempo, la consideración de quienes de hecho no son motivados necesariamente por esta racionalidad instrumental, a subjetividades patologizables desde lo errático o lo irreflexivo.

Ana, por ejemplo, quiso estudiar una especialidad en laboratorio químico, incluso cuando no quería dedicarse a esa especialidad. Ana me cuenta que ella y su familia siempre quisieron que fuese a la universidad y lo logró, estudió Fonoaudiología. Quería hacerlo antes de escoger su especialidad, y aun cuando estudió en un polivalente, donde según lo que cuenta, la elección frente a las modalidades era voluntaria, quiso entrar a la modalidad técnicoprofesional. Cuando decidió entrar a esta modalidad, sentía que el científicohumanista le servía para preparar mejor su PSU, pero de todas formas escogió tener una especialidad, aun cuando en su relato nunca pensó dedicarse a ella y no lo hizo tampoco cuando tuvo que buscar trabajo mientras estudiaba en la educación superior.

Ruth, por su parte, estudió Contabilidad y, al igual que Ana, no se arrepiente, pese a que no se dedicó a eso nunca. Cuando le pregunté a Ruth si pudiese volver al pasado, qué escogería hoy, me respondió que volvería a estudiar en un técnico-profesional y que volvería a elegir Contabilidad, porque gracias a eso pudo realizar una práctica en una minera y aprender a hacer cosas sobre la ecología. Saberes que, aunque no usa ni en su trabajo ni en sus estudios superiores, le gustó aprender, fueron significativos para ella.

Ana no podría haber «adelantado carrera» en un liceo técnicoprofesional, estudió Fonoaudiología y no hay especialidades que correspondan directamente con su profesión. Pero Ruth, sí lo pudo haber hecho; en la educación superior estudió Técnico en Educación Parvularia y su deseo, hasta nuestra última entrevista, era continuar sus estudios para obtener el título profesional. En su liceo, Atención de Párvulos se ofrecía como especialidad, sin 
embargo, mirando retrospectivamente, Ruth volvería a estudiar Contabilidad, entre otras cosas por esa práctica en la minera. Ana y Ruth valoran sus especialidades y su formación técnico-profesional, aun cuando, si sus imágenes del futuro se cumplen, nunca las van a usar profesionalmente. Así y todo, les hacen sentido.

Pareciera que la única manera en que las reglas discursivas de la opción $B$ nos permiten pensar a Ana y Ruth optando por la educación media técnicoprofesional y al mismo tiempo queriendo estudiar en la educación superior, es pensarlas en una formulación estratégica, donde ellas optan por esta modalidad para, por ejemplo, trabajar después en su especialidad y pagar sus estudios superiores. El sujeto posible que concilia los deseos de la educación superior y la educación media técnico-profesional como opción educativa es, precisamente, uno que hace un uso instrumental de esta última. Pero ni Ana ni Ruth encarnan esa formulación y, por lo tanto, sus narraciones sobre sus propios procesos de transición son fácilmente producibles como irracionales, poco estratégicos, etc.

Si me preguntaran a mí lo que yo le pregunté a Ruth, esto es, si pudiese volver al pasado, qué estudiaría en la educación media, yo volvería a tomar electivos de Física y a estudiar Filosofía en la educación superior. No cambiaría mis electivos de Física por más electivos de Filosofía. Aquellos son similares a la práctica de Ruth en la minera. Son experiencias que ambas valoramos, aun cuando no las hemos «usado». En el ejercicio ficticio de volver sobre nuestros pasos, ambas no estamos dispuestas a renunciar a ellas porque fueron significativas. Entonces, ¿por qué me parece que la valoración de mis electivos de Física es tan razonable y en cambio cuando Ruth me habló de su práctica, me dio la sensación de lo contrario?

En mi propio contexto familiar, los saberes científicos tienen un enorme valor que hacen que querer aprenderlos, incluso cuando no los vayamos a utilizar directamente, tenga sentido. Esta valoración de las disciplinas académicas en sí mismas, independiente de su funcionalidad laboral, forma parte importante de las reglas discursivas que dan forma tanto a la educación media técnico-profesional como a mi entorno familiar. Pero ese contexto es específico y no universal, no es el mismo de Ruth o de Ana. La valoración de aprendizajes técnicos tiene condiciones en el contexto de mis entrevistadas, donde en cambio las disciplinas científicas y humanistas padecen de ser demasiado abstractas. Y aunque esto parece una declaración elemental, así y todo, el enunciado de la opción $B$ lo silencia.

Lo que quiero marcar aquí es, precisamente, que la educación media técnico-profesional es parte de un dispositivo, y que una de sus dimensiones es ser una modalidad curricular que brinda un tipo de aprendizajes, así como la formación científico-humanista ofrece otros, no solo en relación con lo que las personas van a dedicarse en el futuro, sino también respecto a qué saberes desean aprender (les sirvan o no), con qué saberes se identifican, qué modalidad 
educativa les hacen sentido. No reconocer esto nos lleva a producir subjetividades patologizadas y trayectorias educativas erráticas. $\mathrm{Si}$ nos mantenemos en la opción $B$ y en la racionalidad instrumental que articula la indeseabilidad asumida de la inserción laboral inmediata, Ana, como sujeto afirmativo (no en falta), es un cuerpo-imposible, o al menos tremendamente improbable. Si Ana fuese el sujeto-estudiante-educación media técnicoprofesional de este enunciado, habría considerado su especialidad en función de la inserción laboral inmediata, o bien para entrar al trabajo directamente, o para entrar al trabajo en su especialidad y tener medios económicos en función de ingresar a la educación superior. Si Ana sabía que no quería dedicarse a su especialidad y quería estudiar en la universidad, ¿por qué no optó por la formación científico-humanista dentro de su polivalente? Ana tenía buenas calificaciones académicas, y tal como ella misma señala, para poder entrar a la universidad, tuvo que preparar la PSU sola, aprender precisamente parte de los saberes científico-humanistas. ¿Por qué no se hizo las cosas más fáciles? O al menos, ¿por qué hoy no piensa que podría haber hecho las cosas de forma distinta? Vanesa, por ejemplo, no volvería a estudiar en un técnico-profesional, precisamente porque siente que fue una pérdida de tiempo. ¿Vanesa es más reflexiva que Ana? Vanesa siente que sería mejor que no hubiese más liceos técnico-profesionales; Ana, en cambio, al igual que Ruth, Denise, Margarita, Beatriz, Carolina, e incluso Ximena, quien tampoco volvería a estudiar en un técnico-profesional, cree que esta modalidad es un buen modelo educativo, que sin duda hay que mejorarlo, pero que es una buena alternativa y que hay que fortalecerla.

En este primer apartado he querido relevar tres líneas discursivas del enunciado de la opción $B$ que distribuyen posiciones diferenciales dentro de nuestro dispositivo educacional actualizando relaciones de fuerza divisorias (sujeto $\mathrm{A}$ /sujeto $\mathrm{B}$, estudiante científico-humanista/estudiante técnicoprofesional, buen estudiante/estudiante «flojito», etc.). Tal como he querido mostrar, estas relaciones de saber/poder reclaman formas articuladas en torno a una racionalidad instrumental para quienes estudian en la educación media técnico-profesional, al mismo tiempo que relegan a subjetividades patologizadas a aquellos que no se ajustan en su trayectoria a esa forma. Pero tal como desarrolla Foucault (2002), las relaciones de saber/poder no son nunca totalizantes, sino que, por el contrario, cada dispositivo está compuesto de enunciados heterogéneos. Que las entrevistadas puedan narrar sus trayectorias educativas de maneras que no se ajustan a las reglas de inteligibilidad de la opción $B$, precisamente nos muestra la insuficiencia de estas líneas discursivas para dar cuenta de las experiencias producidas en la modalidad técnicoprofesional. 


\subsection{EL ENUNCIADO DEL SE APRENDE HACIENDO: SALIR CON ALGO}

Para cada una de las entrevistadas de esta investigación, su formación media estuvo profundamente vinculada al mundo del trabajo. Pero, a diferencia de lo que el enunciado de la opción $B$ hace suponer, esta relación entre educación y trabajo no se da exclusivamente desde una relación de poder impositiva (obligado a), sino que también de deseo. Ruth, por ejemplo, al igual que Margarita y Ana, quiere que su hijo Christopher, de cinco años, en el futuro estudie también en esta modalidad, pese a sentir que la educación media técnico-profesional la formó exclusivamente para el trabajo:

MJ: ¿Y por qué te gustaría que Christopher estudiara en un técnicoprofesional?

R: Porque encuentro que es, como dije recién, una herramienta que él puede adquirir y poner en práctica mucho más rápido para poder surgir y para poder tener él las cosas que él quiera, poder ser un adulto esforzado y más independiente.

(Ruth, tercera entrevista, mayo de 2017)

Me parece que la respuesta de Ruth expresa con claridad lo que me gustaría argumentar en este artículo: la educación media técnico-profesional es sin duda una herramienta, tiene una función instrumental, se entra para poder mejorar las condiciones de vida y tener mejores medios; pero al mismo tiempo, para estas entrevistadas, el valor de esta forma de educación está profundamente vinculado a otros discursos que formulan una comprensión particular del trabajo y su relación con la experiencia educativa y que exceden la racionalidad, las fuerzas impositivas y la instrumentalidad, en la medida en que la educación media técnico-profesional es también un lugar clave para el desarrollo de la propia subjetividad.

Para comprender la valoración que estas mujeres expresan de su formación media, es importante considerar de qué manera en sus experiencias, el conocimiento y los saberes han sido producidos, y qué reglas dan condición en sus vidas a formulaciones valorativas de la educación:

Es que mis papás me criaron así, como que siempre escuché que el científico... como que tampoco a ellos les gustaba mucho el tema, entonces yo siempre me enfoqué en encontrar algo que a mí me gustara, pero que saliera con algún técnico, algún título del colegio, porque igual es como... yo encuentro que es como más valorado salir con un técnico profesional a salir con humanista, porque es como salir del liceo nomás. 
(Ana, primera entrevista, marzo de 2016)

Tal como lo describe Ana, la importancia y el valor de obtener un título en la educación media es algo que la mayoría reconoce como una dimensión clave de su formación, y esta centralidad fue producida en sus contextos. El valor atribuido a este título, sin duda, tiene relación con la posibilidad de la inserción laboral inmediata. Las entrevistadas reconocen que eso fue importante para entrar a la educación media técnico-profesional, y que independientemente de sus expectativas personales, la posibilidad de trabajar inmediatamente después del liceo era un imperativo económico para la mayoría de sus compañeros y compañeras. Sin embargo, aunque la funcionalidad del título que entrega constituye un elemento importante, me parece fundamental no reducir esta valoración de las entrevistadas a una relación meramente instrumental con la modalidad de su formación media. Si bien poseer una especialidad técnica de nivel medio emerge como una herramienta de inserción laboral en algunos momentos de los relatos, en otros también lo hace como una dimensión que da sentido al aprendizaje y valoriza la educación. Un título para el trabajo se constituye como un campo central para significar una experiencia educativa, aquello que para ellas significa estudiar:

D: Yo, en lo que más me enfoco, es que [la educación en general] debería enseñar cosas específicas con la realidad, con lo que efectivamente pasa y con lo que efectivamente se hace en los trabajos, ya sea en empresas, cualquier tipo de trabajo, que enseñen lo que es la realidad.

MJ: ¿Cómo qué tipo de cosas? ¿Se te ocurren ejemplos?

D: Eso, de explayarlo a la realidad. Ponte tú, si explican algo, llevémoslo a un concepto al tiro de la realidad, cosa que la gente al tiro lo asimile o lo capte más rápido porque si es algo que está pasando actualmente, la gente es mucho más fácil que lo entienda, a que lo entienda con una hoja de mil palabras, y que lo leas y lo leas y no captes la idea.

(Denise, tercera entrevista, abril de 2017)

De acuerdo con Foucault (1970), el conocimiento está vinculado a saberes que atraviesan umbrales de epistemologización, cientificidad y formalización, para encarnar formulaciones que en determinadas formaciones históricas le otorgan su estatus (Deleuze, 2013; Foucault, 1970). Me parece que, para las entrevistadas de esta investigación, este umbral corresponde con la practicidad de un saber. La formulación y valoración de estas mujeres sobre el aprendizaje tienen como eje articulador el hacer: se aprende $a$ hacer y se 
aprende en el hacer. Los aprendizajes específicos que ellas destacan de su formación técnico-profesional son precisamente formas prácticas, y tal como Denise recalca, vinculadas a lo que ellas circunscriben a lo real. Desde mi perspectiva, esta es la regla discursiva fundamental que articula las experiencias y valoraciones de estas jóvenes sobre su modalidad educativa, más que la constricción por la inserción laboral (aun cuando, por supuesto, está presente también), es el enunciado del se aprende haciendo.

MJ: Y, por ejemplo, la idea de que hay aprendizaje en relación con el trabajo, ¿Qué valor piensas que le da?

R: Mucho más, porque uno aprende haciendo.

(Ruth, tercera entrevista, mayo de 2017)

Cuando la experiencia de la enseñanza media es formulada desde esta unidad discursiva, muchas veces la educación media científico-humanista queda desvestida de aprendizajes y de sentido para las entrevistadas: se «sale sin nada». Tal como Ana lo expresa, entró a su especialidad para «salir con algo».

Los recuerdos sobre la experiencia en la educación media técnicoprofesional están fuertemente asociados discursivamente al mundo del trabajo, pero esto no es experimentado como una mera alternativa porque no queda otra. Es una fuente de subjetivación fundamental en torno a marcos discursivos que establecen umbrales para el conocimiento. Dicho de otra forma, para estas entrevistadas se aprende un conocimiento cuando se aprende a hacer algo, y esto tiene una valoración positiva para ellas no solo porque responde al imperativo de la inserción laboral inmediata como un efecto de limitaciones, sino que, porque además se produce una relación de deseo de aprender conocimientos prácticos, y estos muchas veces tienen valor, se usen o no.

Este enunciado del aprender haciendo, por una parte, les ofrece fuentes discursivas para resistir, subjetivándose a sí mismas, en formas alternativas a la idea de que tienen peores resultados académicos: saben que su modalidad de estudios no las prepara lo suficiente para la PSU, pero al mismo tiempo, les enseña «algo» (salir con algo), a diferencia de la modalidad que sí lo hace, que desde su perspectiva no les enseña «nada» (salir con nada).

MJ: Te voy a llevar a una pregunta más pa' atrás, esta investigación se trata de mujeres que salieron de educación media técnico-profesional. ¿Tú qué crees que hubiese pasado en tu vida si es que hubieses estudiado en un científico-humanista

D: No sé... no sé, la verdad, yo creo que no hubiese estado... tan bien 
como ahora, yo creo que me hubiese costado mucho más estudiar, mucho más de lo que me ha costado ahora.

MJ: ¿Y por qué? ¿Por qué tienes esa sensación?

D: Porque encuentro que los científicos, ¿cómo se llaman?

MJ: Científico-humanistas...

D: Ya, los científicos solamente te preparan para la PSU, yo creo que la PSU no mide todo... porque, a ver, la PSU es para entrar a una universidad buena, ¿no cierto? A lo mejor no pagando y todo eso, pero no creo que sea tan bueno lo que mide.

(Denise, segunda entrevista, octubre de 2016)

Igual los técnicos encuentro que tienen una buena metodología, dentro de todo, porque te dan la posibilidad de estudiar algo más avanzado dentro del liceo que un científico-humanista.

(Ruth, tercera entrevista, mayo de 2017)

Al mismo tiempo, les permite legitimar sus propias trayectorias y subjetivarse en ellas, no como jóvenes irreflexivas o que tomaron decisiones erráticas, sino como buenas estudiantes que han recorrido un camino que les ha enseñado cosas valiosas, algunas de las cuales han usado, y otras no, pero que sin duda ambas tienen sentido porque no solo hay imposición de aprender saberes técnico-profesionales, sino también deseo de hacerlo, y entonces aprender laboratorio químico o contabilidad son una experiencia valiosa, independiente de su uso posterior.

Más que la especialidad en concreto como oportunidad para la inserción laboral temprana, sino que la modalidad técnico-profesional, como oportunidad de aprender ciertas formas de hacer y ser, que están imbricadas en el trabajo como lugar de identificación, constituye la fuente de subjetivación más intensa de su experiencia en la educación media técnico-profesional y las condiciones para su valoración casi transversal:

Yo encuentro que lo que me enseñaron en la media y en este colegio fue la parte de seguir aprendiendo, seguir estudiando, de que ser esforzada, de que si quiero algo haga todo lo posible para poder conseguirlo. Creo que eso es lo que me ayudó harto el colegio, de que siempre salga adelante, de que todos los días trate de aprender algo más, creo que eso, de que no me deje estar.

(Margarita, segunda entrevista, octubre de 2016) 
La educación media técnico-profesional les enseña algo para ellas mucho más importante que la especialidad en particular; les enseña a hacer y ser personas trabajadoras, a tener las cosas por ellas mismas. Sobre todo, el esfuerzo, la responsabilidad y la independencia son subjetividades que se repiten con insistencia en las entrevistas. Para las entrevistadas, estos son las grandes cualidades que les dio la modalidad técnico-profesional.

Como te están preparando pa' trabajar, entonces como que te enseñan como que tú tienes que ser responsable, tienes que ser puntual, el compañerismo, el respeto. Entonces, no es que en un científico comercial no te lo enseñen, claro, pero acá como que te lo fomentan. Te fomentan más a ser como «tú tienes que ser una persona responsable, porque el día de mañana tú vas a estar trabajando en lo que estudiaste, entonces, tú no puedes, así como llegar a la chacota con tus compañeros, como que estuvieran en el colegio». Yo creo que por ese lado te lo fomentan un poco más en el técnico-profesional.

(Ximena, segunda entrevista, noviembre de 2016)

MJ: Además de darte una especialidad, como el título más específico, ¿tú sientes que la educación técnico-profesional te enseña algunos valores específicos?

R: Sí.

MJ: ¿Qué valores?

$\mathrm{R}$ : Responsabilidad, independencia y compromiso.

MJ: ¿El compromiso con qué?

$\mathrm{R}$ : Con tu trabajo. Con la carrera que uno elige.

(Ruth, tercera entrevista, mayo de 2017)

Los relatos de casi ninguna de las entrevistadas dan cuenta de una experiencia escolar sujeta a las reglas de la opción B. En cambio, la mayoría valora profundamente su formación, algunas creen que es mejor que la educación científico-humanista y la gran mayoría volvería a estudiar en esta modalidad.

Como contrapunto al enunciado de la opción $B$, y con el objetivo de identificar reglas discursivas que hicieran posible la valoración de las entrevistadas sobre su modalidad de estudios, distinguí el enunciado del se aprende haciendo. Este enunciado establece reglas discursivas en torno a los saberes entregados por la educación media profundamente distintas a las que moviliza el enunciado de la opción B. A diferencia de una visión meramente instrumental de aprender especialidades vinculadas al trabajo, para las 
entrevistadas el umbral que hace devenir un saber en conocimiento es, precisamente, su practicidad. Y, por lo tanto, la educación media técnicoprofesional desde sus relatos no solo les entregó herramientas funcionales con el trabajo, sino que, en esa misma relación, los aprendizajes técnicos devienen aprendizajes significativos, más allá incluso de su funcionalidad concreta en sus trayectorias posteriores. Además, desde mi perspectiva, este enunciado está profundamente vinculado con una práctica de subjetivación de clase, que produce distinciones para las entrevistadas entre su propia forma de entenderse y la forma en que clasifican a otras subjetividades que constituyen el límite de sus propias subjetividades: los cuicos y los flaites. Aprender a hacer y haciendo circunscrito al trabajo es fundamental, porque hacer las cosas por uno mismo y ser trabajador es lo que las distingue de aquellas subjetividades que se les muestran como otros y otras. Por una parte, los cuicos son muchas veces formulados como sujetos que no tienen nada por ellos mismos, y que ocupan un lugar de privilegio pese a no saber hacer; y los flaites, sujetos más próximos, son producidos como carentes de aspiraciones y racionalidad y que, por lo tanto, tampoco tienen nada por ellos mismos. Con esto, por supuesto, no quiero defender estos modos de subjetivación, sino simplemente marcar que operan y que son profundamente distintos a los que la opción $B$ despliega.

\section{REFLEXIÓN FINAL}

Proponiendo la extracción del enunciado que he denominado opción $B$, he querido relevar una regla de inteligibilidad que, desde mi perspectiva, circula dentro de nuestro dispositivo educacional, imputando significados a la educación media técnico-profesional y sus estudiantes, y que considero clave cuestionar al momento de comprender las experiencias en esta modalidad. Este enunciado produce silenciosamente a las y los estudiantes de la educación media técnico-profesional como otras y otros de la modalidad científicohumanista. Desde una racionalización desanclada de los entornos culturales de ellas y ellos, este enunciado asume que, constreñidos previamente por condiciones económicas y/o académicas, entran a la educación media técnicoprofesional porque, constatando esas constricciones, nos les queda otra que optar por ella, dando por hecho que en otras condiciones (mejor situación económica y/o académica) hubiesen deseado entrar al científico-humanista. El enunciado de la opción B nos hace asumir la visibilidad de la segmentación que articula ambas modalidades en términos socioeconómicos y académicos, la visibilidad de la existencia de ambas modalidades, pero sobre todo la deseabilidad de la educación media científico-humanista por sobre la alternativa técnico-profesional.

Desde mi propia experiencia como estudiante de educación media en su versión científico-humanista privada, la educación media técnico-profesional ocupó siempre un espacio de escasa visibilidad, y ese silencio fue reafirmado en 
mi experiencia universitaria como estudiante de Filosofía y luego de Pedagogía. Hablo de mi propia experiencia porque creo que esta no es arbitraria o marginal, sino que responde a parte de las líneas enunciativas y de fuerzas que articulan nuestro dispositivo de educación y las miradas que ofrecemos sobre sus partes. Tal como para mí la educación media técnico-profesional ha padecido de escasa visibilidad, también lo ha hecho para la política y los estudios de investigación educativa, pese a concentrar a casi la mitad de los estudiantes de nuestra educación media en las últimas décadas. Si aceptamos la invitación de Foucault a pensar que los dispositivos están constituidos por regímenes de saber/poder, donde distintas posiciones se diseminan en el espacio social, entonces esta escasez de visibilidad debe ser explorada más allá de considerarla como un mero dato de la causa. No es arbitrario que produzcamos escasa investigación sobre la educación media técnico-profesional en Chile, y tampoco lo es, que tanto esta modalidad como quienes estudian en ella no sean actores centrales de los debates educativos y los discursos políticos en educación. No es arbitrarios que los líderes estudiantiles provengan en su mayoría de la educación media científico-humanista, al igual que quienes ocupan lugares dentro del Ministerio de Educación o dentro de las instituciones dedicadas a las investigaciones académicas.

El dispositivo educacional nos hace, a muchos de quienes no fuimos formados en esta modalidad, hablar nada o muy poco de esta. Pero los dispositivos son heterogéneos. Implican regímenes de visibilidad y enunciación distintos, de acuerdo con la posición que ocupamos dentro de ellos. Así, mientras para algunos (la política, la investigación, la educación privada, etc.) la luz sobre la educación media técnico-profesional es escasa y tiende a ser producida desde la centralidad de la modalidad científico-humanista; para otros y otras, entre ellos muchas de las entrevistadas de esta investigación, ocurre precisamente lo contrario.

Esta duplicidad que mantiene una relación profundamente segmentada respecto a los discursos sobre la educación media y sus modalidades implica, por ejemplo, que hoy alguien pueda decir: «Yo encuentro que es como más valorado salir con un técnico profesional a salir con humanista, porque es como salir del liceo nomás» (Ana, primera entrevista) y que simultáneamente en otro lugar se pueda decir también: "Pero en nuestro país hoy la educación técnica es casi lo que botó la ola» (Mirentxu Anaya, presidenta ejecutiva de Educación 2020). Ambas frases son posibilitadas por nuestros dispositivos, ambas conviven y tienen significados.

Frente a esta fractura que impone el régimen discursivo que articula nuestro sistema educacional, una posición es reiterar la patologización, formulando una jerarquía, y reduciendo la creencia de Ana a una ingenuidad o ignorancia. Otra alternativa es explorar esta convivencia de proposiciones y las reglas que las hacen posibles, así como las relaciones de fuerza que las articulan. Pero también, desde mi perspectiva, implica para quienes no fuimos 
formados en la educación media técnico-profesional, pero que sin embargo hablamos de ella, hacernos responsables y sensibles de nuestras palabras y sus efectos. Hablar desde el enunciado de la opción $B$ tiene un efecto preocupante. Todas las citas incluidas en este artículo son frases que sin duda dan cuenta de la inquietud por las desigualdades estructurales que recorren nuestro sistema educativo. Pero al mismo tiempo, desde mi perspectiva, reafirman y produce una inevitable patologización de sus actores, al producir a las y los estudiantes de la educación media técnico-profesional como sujeto otro. Denunciando sin duda la desigualdad, pero al mismo tiempo performateando su naturalización y las posiciones de privilegio que muchos ocupamos.

La desigualdad que recorre nuestro sistema, materializada en modalidades que ofrecen aprendizajes de naturaleza distinta, no está anclada en la diferencia de estos aprendizajes, sino en las relaciones de poder/saber en que esos aprendizajes adquieren inteligibilidad. En nuestro contexto, lo problemático no es un currículo de saberes técnicos, sino las relaciones de saber/poder a las cuales está subordinado.

Me parece que, en el campo de las investigaciones y las discusiones políticas en torno a la educación media técnico-profesional, debemos avanzar en producir lecturas que insistan en el efecto de las constricciones socioculturales, pero que no reduzcan las experiencias a ellas, y que busquen problematizar algunas dimensiones discursivas que transitan de forma naturalizada por espacios del debate educativo. El debate en torno a la educación media técnico-profesional debe estar informado por posiciones sensibles a las subjetividades y deseos de quienes son formados en esa modalidad, pero además debe apoyarse en una mirada reflexiva respecto a cómo nuestras posiciones de clase, género, generación, etc., constelan nuestra manera de ver y nombrar a la educación media técnico-profesional. El discurso de la opción $B$ no solo no da cuenta de las experiencias de sus estudiantes y familias, sino que, además, refuerza las desigualdades que recorren nuestro sistema educativo. No podemos aceptar que el sistema se conciba con opciones de primera y segunda, por el contrario, tenemos que dirigir nuestros esfuerzos políticos hacia la producción de un sistema educativo equitativo que ofrezca oportunidades pertinentes y que legitime la diversidad de deseos y situaciones de las y los estudiantes y sus contextos.

RECIBIDO: 14 DE MARZO DE 2019

ACEPTADO: 19 DE JUNIO DE 2019 


\section{BibLiOGRAFÍA}

ANAYA, M. (s.f.). «Opinión: \#MejoraLaTécnica: No permitamos que la mitad de la educación chilena esté olvidada por completo». Educación 2020, Santiago, Chile. Disponible en: https://www.eldinamo.cl/blog/mejoralatecnica-no-permitamos-que-lamitad-de-la-educacion-chilena-este-olvidada-por-completo/

ARRIAGADA, I. (2018). «Desafíos de la educación media técnico-profesional». Grupo Educar, Santiago, Chile. Disponible en: https://www.grupoeducar.cl/noticia/desafios-de-la-educacion-mediatecnico-profesional/

BALL, S. (2012). Foucault, Power and Education. Londres: Routledge.

Butler, J. (2001). Mecanismos psíquicos del poder: Teoría sobre la sujeción. Valencia: Universitat de València/Ediciones Cátedra.

Deleuze, G. (1987). Foucault. Barcelona: Paidós. . (2013). El saber. Curso sobre Foucault. Buenos Aires: Cactus.

FARÍAS, M. y CARRASCO, R. (2012). «Diferencias en resultados académicos entre la educación media técnico profesional y humanista científica en Chile». Revista Calidad en la Educación, 36: 88-121.

FARÍAS, M. y SEVILlA, M. P. (2015). «Effectivness of Vocational High Scools in Students' Access to and Persistence in Postsecondary Vocational Education». Research and Higher Education, 56(7): 693-718. doi: 10.1007/s11162-015-9370-2

Foucault, M. (1970). La arqueología del saber. México, D.F.: Siglo XXI. (1984). «La ética del cuidado de sí como práctica de la libertad». En Estética, ética y hermenéutica. Obras esenciales, Vol. III. Barcelona: Paidós, 1999.

. (1991). «El juego de Michel Foucault». En Saber y verdad. Madrid: Ediciones de La Piqueta.

. (2002). Vigilar y castigar. Nacimiento de la prisión. Buenos Aires: Siglo XXI.

GIL, F. J. (2015). «No dar respuesta a esos miles de jóvenes de colegios pobres es un acto de violencia». Educación 2020, Santiago, Chile. Disponible

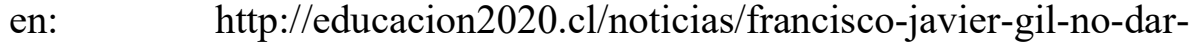
respuesta-a-esos-miles-de-jovenes-de-colegios-pobres-es-un-acto-deviolencia/

HERnÁnDEZ, M. (2015). ¡Feliz día de la Educación media técnico-profesional! Educar Chile, Santiago, Chile. Disponible en: http://ww2.educarchile.cl/Portal.Base/Web/VerContenido.aspx?GUID= 
e13d3ef4-5136-4f9e-a182-a9ba9b89d141\&ID=227365

Larrañaga, O., Cabezas, G. y Dussaillant, F. (2014). «Trayectorias educacionales e inserción laboral en la enseñanza media técnico profesional». Estudios Públicos, 134: 7-58.

. (2013). «Informe completo del Estudio de la Educación Técnico Profesional». Programa de las Naciones Unidas para el DesarrolloChile. Área de Reducción de la Pobreza y la Desigualdad.

Lawler, S. (2000). Mothering the Self: Mothers, Daughters, Subjects. Londres: Routledge.

Ministerio DE EdUCACiÓN. (2015). «Educación Media. Santiago, Chile». Portal Web Educación técnico-profesional. Disponible en: http://www.tecnicoprofesional.mineduc.cl/educacion-media-tecnicoprofesional/

. (2018). Informe: Estadísticas de la Educación. Santiago: Centro de Estudios Ministerio de Educación.

MuÑoz, C. (2013). «Educación Técnica Profesional: Una ausencia imperdonable». Educación 2020, Santiago, Chile. Disponible en: http://educacion2020.cl/noticias/educacion-tecnica-profesional-unaausencia-imperdonable/

SEPÚlvedA, L. (2016). «Trayectorias educativo-laborales de jóvenes estudiantes de educación técnica en Chile: ¿Tiene sentido un sistema de formación para el trabajo en la educación secundaria?». Páginas de Educación, 9(2): 49-84.

SePÚlvedA, L., Ugalde, P. y CAmpos, F. (2009). Estado y perspectivas de la enseñanza media técnico profesional en Chile: un estudio sobre las orientaciones estratégicas predominantes en los actores. Fonide $\mathrm{N}^{\mathrm{o}}$ F310831-2008. Santiago: Ministerio de Educación.

. (2010). La enseñanza media técnico profesional en Chile. Orientaciones actuales desde la perspectiva de sus actores. Santiago: CIDE, Universidad Alberto Hurtado.

Sepúlveda, L. y Valdebenito, M. J. (2014). «Aspiraciones y proyectos de futuro de estudiantes de enseñanza técnica-profesional ¿Es pertinente un sistema diferenciado de enseñanza media?». Polis [en línea], 38: 1-18. Disponible en: http://polis.revues.org/10269. doi: 10.40000/polis.10269

SEvilla, P. (2014). «La educación técnica en Chile y Estados Unidos desde una perspectiva histórica y comparada». Calidad en la Educación, 40: 298-317. doi: /10.4067/S0718-45652014000100010

Sevilla, P., Farías, M. y Weintraub, M. (2014). «Articulación de la Educación Técnico Profesional: una contribución para su comprensión y 
consideración desde la política pública». Calidad en la Educación, 41: 83-117.

SkegGS, B. (1995). Introduction. En B. SkegGS (Ed.), Feminist cultural theory process and production. Manchester y Nueva York: Manchester University Press.

Youdell, D. (2006). Impossible Bodies, Impossible Selves: Exclusion and Student Subjectivities. Londres: Springer.

Walkerdine, W., Lucey, H. y Melody, J. (2001). Growing Up Girls. Nueva York: New York University Press. 